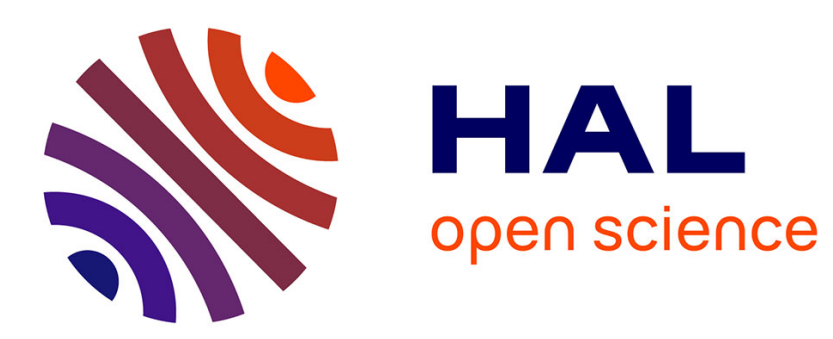

\title{
What Can You Expect? The Influence of Gender Diversity in Dyads on Work Goal Expectancies and Subsequent Work Commitment
}

\author{
Floor Rink, Naomi Ellemers
}

\section{- To cite this version:}

Floor Rink, Naomi Ellemers. What Can You Expect? The Influence of Gender Diversity in Dyads on Work Goal Expectancies and Subsequent Work Commitment. Group Processes and Intergroup Relations, 2006, 9 (4), pp.577-588. 10.1177/1368430206067560 . hal-00571632

\section{HAL Id: hal-00571632 \\ https://hal.science/hal-00571632}

Submitted on 1 Mar 2011

HAL is a multi-disciplinary open access archive for the deposit and dissemination of scientific research documents, whether they are published or not. The documents may come from teaching and research institutions in France or abroad, or from public or private research centers.
L'archive ouverte pluridisciplinaire HAL, est destinée au dépôt et à la diffusion de documents scientifiques de niveau recherche, publiés ou non, émanant des établissements d'enseignement et de recherche français ou étrangers, des laboratoires publics ou privés. 


\title{
What Can You Expect? The Influence of Gender Diversity in Dyads on Work Goal Expectancies and Subsequent Work Commitment
}

\author{
Floor Rink and Naomi Ellemers \\ Leiden University
}

\begin{abstract}
In an experimental study $(N=60)$ we showed that gender differences play an important role in the extent to which people expect work goal differences between themselves and their collaborating partner. Participants who interact with a same-sex partner expect this person to pursue the same work goal as the self, whereas those who interact with an opposite-sex partner expect this person to have a different work goal to the self. When these expectancies were confirmed, participants felt relatively little disappointment, developed a clear image of their partner, and felt committed toward future collaboration. However, an expectancy violation caused participants to respond relatively negatively on these measures. These effects are discussed in relation to expectancy violation and congruence theory.
\end{abstract}

KEYWORDS congruence, decision making, dyads, expectancy violation, gender differences, work goals

A RECENT review on organizational diversity showed that over the last five years, gender has become one of the most frequently examined demographic attributes in this field (Jackson, Joshi, \& Erhardt, 2003). This is not surprising, given that gender differences are highly common within groups (or dyads) and can have a strong influence on the interpersonal relationships between people (Jackson et al., 2003; for a review see Williams \& O'Reilly, 1998; see also Fiske \& Taylor, 1991). More recently, diversity researchers have also started to examine the influence of differences in taskrelated attributes on group and dyadic functioning as they are expected to have a more direct impact on decision making processes and outcomes (Pelled, Eisenhardt, \& Xin, 1999;

\section{Author's note}

Address correspondence to Floor Rink, Department of Social and Organizational Psychology, Leiden University, PO Box 9555, 2300 RB Leiden, The Netherlands [email: rink@fsw.leidenuniv.nl] 
Webber \& Donahue, 2001). One such important task-related diversity attribute is the difference between people in the personal work goals that they prefer to pursue during a collaboration (i.e. also referred to as work value diversity; Jehn, Northcraft, \& Neale, 1999). In this contribution, we address the relationship between gender differences and work goal differences during the initial stages of task interactions within dyads. We believe that the gender composition of a dyad determines whether people expect their collaborating partner to prefer the same work goal as the self or a different work goal prior to the first interaction. Moreover, we argue that, compared to the situation where these expectations are confirmed, a violation of gender-based expectations will lead people to feel disappointed, to develop a relatively unclear image of their partner, and to reduce their level of commitment toward future collaboration with the partner.

\section{Work goal diversity and gender diversity}

In this study, we specifically focus on differences in work goals, because this represents an important but empirically neglected characteristic of work groups (Connor \& Becker, 1975; Dose, 1997). That is, even though there is relatively little literature on the effects of work goal differences at work, this type of taskrelated difference between group or dyad members is highly relevant to collaborative interactions. Work goal differences typically influence the effectiveness of task groups because they indicate what kind of tasks people personally prefer to perform and what they individually prefer to obtain from working with a particular other (Dose, 1997). Jehn et al. (1999) were among the first to examine how differences in personal work goal preferences can influence group performance, and found that such differences could be very problematic for group functioning. Jehn et al. explained this finding by arguing that personal work goal differences are often not immediately visible within a group, and only tend to become apparent over time when people start to express their personal preference to obtain a particular goal through the exchange of personal information (see also Gruenfeld, Mannix, Williams, \& Neale, 1996; i.e. deep-level diversity, Harrison, Price, \& Bell, 1998; Harrison, Price, Gavin, \& Florey, 2002; Webber \& Donahue, 2001). As a consequence, it is relatively difficult for group members to effectively manage work goal differences within their group.

Because it is often rather difficult to observe a personal work goal of others, we believe that people's initial expectations about the work goals of others can play an important role, and may even determine the way actual similarities or differences are perceived during a first encounter. We aim to contribute to existing insights in this area of research by examining how more visible gender differences relate to people's expectations of possible work goal differences. In addition, we will test whether group members find it easier to deal with work goal differences when they have reason to expect such differences to occur than when such differences violate previous (similarity) expectations. Thus, we predict that dyads will be better able to cope with work goal differences when these are in line with already existing gender differences, than when this is not the case.

\section{Gender-based expectancies}

Several diversity researchers have explained the potential value of demographically diverse groups by pointing at the presumably close relationship between these differences and more 'underlying' cognitive and task-related differences between group members (Jackson et al., 2003; Lawrence, 1997). This reasoning suggests that people make inferences about the way in which their own personal work goals may differ from those of others at work on the basis of visible demographical characteristics, such as gender. Furthermore, these inferred differences in work goals are expected to determine how the members react toward each other (i.e. the trait model; Fiske \& Taylor, 1991; McGrath, Berdahl, \& Arrow, 1995; see also Nickerson, 1999). 
However, this prediction has never been directly examined. In fact, some other researchers have argued that regardless of demographic differences, people also have the tendency to develop similar expectations of others they work with on the basis of their joint group membership (Bettencourt, Dill, Greathouse, Charlton, \& Mulholland, 1996; see also Miller \& Marks, 1982). Therefore, we aim to examine whether people will indeed expect congruence between the demographic and task-related attributes of their collaborating partners. That is, do people expect a demographically different other to possess different task-related characteristics as well? In relation to dyadic collaboration, this would mean that a man and a woman who work together will most likely expect to prefer different work goals, whereas two females (or two males) who work together expect to prefer the same work goals. Alternatively, it is possible that due to the fact that they jointly work on the same task, they expect this other to possess similar task-related characteristics as the self, regardless of their already existing demographic differences. Thus, in the present research, we aim to test whether gender diversity and work goal diversity are in fact related to each other. In doing so, we will be able to fill an important empirical gap by testing the basic assumptions underlying the trait-model of diversity effects (McGrath et al., 1995).

Our central prediction is;

H1: People will expect an opposite-sex partner to prefer a different work goal as the self, and a samesex partner to prefer a similar work goal as the self.

\section{Expectancy violation}

It is not only interesting to examine whether or not people develop gender-based expectations of their dyad partner's work goal preference, but also whether a violation (or confirmation) of such expectations in the interaction with this partner influences the further reactions of people toward the other and their beginning collaboration. Initial responses and first impressions can influence the extent to which people are willing to make an effort to optimize the collaboration with another person, and can thus work as self-fulfilling prophecies (see expectation-states theory, Berger, Fisek, Norman, \& Zelditch, 1977; Berger, Ridgeway, Fisek, \& Norman, 1998; Oldmeadow \& Postmes, 2005). Therefore, we believe that it is highly important to examine whether diversity expectancies will influence the effects of actual differences during a collaboration.

Expectancy-violation theory states that when our expectations of fellow group (or dyad) members are violated (i.e. incongruence), we feel disappointed and evaluate these others more negatively than when our expectations are confirmed (i.e. congruence; Bettencourt et al., 1996; Biernat, Vescio, \& Billings, 1999; see also Jost, Kruglanski, \& Nelson, 1998; Phillips, 2003). Thus, it seems that it is not essential whether the other is similar or different to the self, but whether or not this is in line with previous expectations. A recent study on the impact of congruence on the functioning of diverse groups is in line with the assumption that people expect certain types of differences to exist in combination with each other (Phillips, Mannix, Neale, \& Gruenfeld, 2004). Phillips et al. found that people were better able to recognize and use novel information (i.e. a task-related attribute) about a group member who was previously unknown to them than when this information came from a group member with whom they already had developed social ties. This finding was explained by arguing that people generally expect a stranger to be different from the self (i.e. congruence), whereas they do not expect to differ from a familiar person (i.e. incongruence; see also Thomas-Hunt \& Phillips, 2004). Unfortunately however, Phillips et al. did not specifically measure whether people actually held such category-based expectancies about task-related features of their fellow group members.

Work of Eagly and colleagues on the social role theory of gender differences also supports the notion that gender-based expectancies can play an important role in how people react toward others in a work situation (Eagly \& Karau, 2002; Eagly, Karau, \& Makhijani, 1995). 
Eagly has demonstrated that for women, effective leadership behavior is rated less favorably than for men who display the same behavior, because such leadership behavior is perceived as being incongruous with the female gender role (see also Carli, LaFleur, \& Loeber, 1995). For instance, research on the effects of gender stereotypes shows that when individual men or women disconfirm gender stereotypic expectations, this causes them to be evaluated more negatively, even when the counterstereotypic behavior is functional to the task at hand (Eagly \& Karau, 2002; Kunda \& Spencer, 2003). Thus, similar and effective behavior is judged differently depending on whether this behavior confirms or violates previous expectations. Importantly, Eagly et al. have specifically focused on the influence of gender-stereotypical expectations on task interactions. Yet, so far it remains unclear whether people also develop gender-based expectations about more neutral, non-stereotypical task-related attributes, like similarities or differences in work goal preferences.

To conclude, previous research seems to indicate that people should be better able to effectively deal with task-related differences (e.g. in terms of work goals) between the self and a work partner when they expected these differences to occur within the dyad prior to the first collaboration. In that case, people can anticipate this situation (see also Ely \& Thomas, 2001; Stasser \& Titus, 1985). Thus, we will specifically examine whether expectancies based on gender differences can help people to accept work goal differences between themselves and others they have to work with. In addition, we will investigate whether people also react negatively toward a violation of expected work goal differences between the self and the collaborating partner (when they turn out to be similar to each other).

When people are confronted with an expectancy violation, they report feelings of disappointment. Furthermore, they appraise the situation as uncontrollable and feel powerless (Frijda, Kuipers, \& Ter Schure, 1989; Zeelenberg, van Dijk, Manstead, \& van der Pligt, 1998). As a result, they will develop a negative attitude toward the other. From this, we infer that a violation of clear expectations may also influence the extent to which people form a clear picture of the other and are motivated to collaborate with their partner. We will therefore also examine the image that people develop of the other and the extent to which people are committed toward future collaboration.

Based on the notion that in principle any kind of expectancy violation should elicit negative reactions from people (Burgoon, Le Poire, \& Rosenthal, 1995), our second hypothesis is that:

H2: When actual work goal differences are expected (because people have to collaborate with an opposite-sex partner; i.e. expectancy confirmation), participants will be less disappointed, develop a relatively clear image of their partner and be more committed toward future collaboration than when these differences are not expected to occur (because people have to collaborate with a same-sex partner; i.e. expectancy violation).

\section{Method}

\section{Design and respondents}

In a 2 (Gender: Similar vs. Different) $\times 2$ (Work Goal Preference: Same vs. Different) between-subjects experimental design we simulated the collaboration of dyads on a decision making task. The participants consisted of 60 female undergraduate students at Leiden University (average age, $M=20.97$ ) who were randomly allocated to the four experimental conditions ( $N=15$ participants per condition). At the end of the experiment, participants were debriefed and thanked for their participation. Participants either received course credits or were paid 4 Euros (approximately US\$5.50) for their participation.

\section{Procedure and decision making task}

Participants were seated in front of a computer that was placed in one of eight separate cubicles. This way, they were not able to see or hear other participants. Participants were told that the university was collaborating with three organizations in the context of a large research program and was specifically looking for two students to assist in parts of the program during 
their internship. Participants were assigned to a dyad with another student and were led to believe that together, they had to choose one out of the three organizations for this joint internship. Participants received all the information about the task, the manipulations and dependent measures individually via the computer.

The task allegedly consisted of two phases. In phase one, participants had to choose one out of two possible goals that they personally would pursue during this internship and were asked to inform the dyad partner about their work goal preference via the computer. In return, the partner allegedly informed participants about his or her selected work goal. In the second phase of the study, participants supposedly would enter a face-to-face discussion with their dyad partner to come to a final decision. However, in reality this discussion did not take place and all information supposedly coming from the dyad partner via the computer was preprogrammed and experimentally simulated. After the information exchange in phase one, participants were asked to complete a questionnaire and were told that the experiment was in fact finished. They were debriefed and thanked for their cooperation.

Before we provide a more detailed description of the experimental manipulations in our main study, we will first describe the pretesting procedure for the two work goals that were offered to participants.

\section{Development of task-related features}

The two work goals that we used were: (1) gaining practical experience; or (2) gaining research experience. ${ }^{1}$ We first tested prior to the experiment whether these two work goals were equally important to students and were not considered to be either typically feminine, or typically masculine. We therefore asked 29 independent participants from the same student population ( 15 female and 14 male participants) to rate how important they considered the achievement of each goal during an internship. In addition, they had to indicate the extent to which they believed each work goal would appeal to both men and women. All questions were answered on 7-point scales $(1=$ Not at all to $7=$ Very much). The results of this pretest indicated that gaining practical experience during an internship was considered just as important $(M=6.14, S D=.80)$ as gaining research experience $(M=5.86, S D=.79)(t(28)$ $<1, p=n s)$. In addition, participants believed that gaining practical experience was considered to be an equally important goal for men $(M=5.89, S D=1.05)$ as for women $(M=6.10$, $S D=.90)(t(28)<1, p=n s)$. As intended, this was also the case for gaining research experience $(M=5.66, S D=1.08 ; M=5.59, S D=.87$ respectively) $(t(28)<1, p=n s)$.

\section{Main study}

Gender composition At the start of the experiment, participants had to exchange their name, age and gender with the dyad partner via the computer. In the same-sex conditions, participants thought they had been assigned to a 20 year old female dyad partner called 'Maartje'. In the opposite-sex conditions, they were assigned to a 20 year old male partner called 'Maarten'. From this point on, the computer either referred to the dyad partner's name or to 'he' or 'she' when participants received information from the dyad partner. This gender manipulation was checked with one statement: My dyad partner is (1) of the same sex; or (2) of the opposite sex.

Personal work goal preference After participants had received the background information of their dyad partner, they were asked to select one work goal that they personally found most important to pursue during an internship. Once participants had indicated their own preference, we stimulated further internalization of this work goal by providing additional information about the importance of the goal. Participants were assured that their personal work goal preference was indeed an important goal that could be obtained from an internship. In addition, they were told that people generally attach great value to their personal work goal. Participants were subsequently asked two questions about their dyad partner's work goal preference: 'I expect my dyad partner to prefer 
gaining practical experience'; and 'I expect my dyad partner to prefer gaining research experience' $(1=$ Not at all to $7=$ Very $m u c h)$. Depending on the personal work goal that the participants had selected, we later recoded these questions into two measures indicating the extent to which participants expected their dyad partner to prefer the same work goal as themselves, or the extent to which they expected the partner to prefer a different work goal. Then, participants received information about the three organizations so that they would be well prepared for the upcoming discussion.

Work goal preference dyad partner When participants had finished reading the organizational profiles, they were asked to inform their dyad partner about their personal work goal preference. In return, they allegedly received the actual work goal preference of the dyad partner. In doing so, they would be better able to take each other's interests into account during the discussion. In the same preference conditions, participants found out that the dyad partner preferred the same work goal as themselves, whereas in the different preference conditions, participants were led to believe that the dyad partner had actually selected a different work goal. This manipulation was checked with one question: 'It turns out that my partner actually prefers: (1) The same work goal as myself; or (2) A different work goal as myself.' In addition, we asked one question to check the experience of expectancy violation: 'To what extent have your expectations about the work goal of your dyad partner been violated?' $(1=$ Not at all to $7=$ Very much).

\section{Dependent measures}

After this computerized interaction, participants had to complete a questionnaire containing our dependent measures, namely: (1) the level of disappointment; (2) the image of the dyad partner; and (3) feelings of commitment toward future collaboration. First, the level of disappointment was measured with one item: 'To what extent do you feel disappointed at this moment?' Subsequently, two items were used to measure whether participants could develop a clear image of their dyad partner: 'At this moment, I have a clear impression about my dyad partner' and 'At this moment, I can form a clear picture of my partner' $(\alpha=.63)$. Finally, participants further completed three items assessing the extent to which dyad partners felt committed toward future collaboration with their dyad partner: 'In the upcoming discussion, I want to make an effort to reach a successful joint decision', 'I am highly interested in the upcoming discussion', and 'During the upcoming discussion, I will definitely take the arguments of my dyad partner into account' $(\alpha=.74)$. All items were rated on a 7-point scale anchored by 'Not at all' (1) to 'Very much' (7).

A Principal Component Analysis with varimax rotation confirmed that the items measuring the image of the dyad partner and commitment toward future collaboration loaded on two orthogonal factors and thus refer to two independent constructs. There were no crossloadings greater than .29. Each factor had an eigenvalue above 1 and together they explained $65.87 \%$ of the total amount of variance.

\section{Results}

\section{Manipulation checks}

Depending on the experimental conditions, participants always gave the correct answer to the question whether their dyad partner was of the same sex or of the opposite sex, indicating that our gender composition manipulation was successful. Likewise, all participants in the same preference conditions indicated that the dyad partner preferred the same work goal as themselves, whereas all participants in the different preference conditions indicated that the partner preferred a different work goal. Thus, our manipulation of the dyad partner's actual work goal preference was successful as well.

Self-activated expectations We conducted a repeated measures analysis with the two expectancy measures for the dyad partner's work goal preference as within-subject factors and gender as the between-subject factor to test whether the expectations of participants about 
the work goal of their dyad partner was indeed related to the gender composition within the dyads (see McGrath et al., 1995). As intended, we found a significant interaction effect between self-activated expectations of the dyad partner's work goal preference and gender $\left(F(1,58)=21.95, p<.001, \eta^{2}=.28\right)$. In the opposite-sex conditions, participants were significantly more likely to expect that their dyad partner would prefer the other work goal $(M=$ $4.50, S D=1.11)$ than the work goal that they had selected themselves $(M=3.53, S D=.94)$. In same-sex conditions, however, participants were significantly more likely to expect that the partner would prefer the same work goal as they $\operatorname{did}(M=4.90, S D=1.06)$, than the other work goal $(M=3.80, S D=1.06)$. This finding is in line with our hypothesis and provides evidence for the notion that demographically different dyad members (i.e. in terms of gender) tend to assume that they are also different in other more task-related features (i.e. in their personal work goals). ${ }^{2}$

The results for the expectancy violation check and our dependent measures were obtained by performing a series of analyses of variance (ANOVAs) with Gender Composition (Similar vs. Different) and the Work Goal Preferences (Similar vs. Different) as betweensubject factors. ${ }^{3}$

Expectancy violation The results for expectancy violation revealed a significant interaction effect with the predicted pattern of means $\left(F(1,56)=16.39, p<.001, \eta^{2}=.23\right)$. As predicted, subsequent simple main effects analysis confirmed that participants indeed experienced more expectancy violation when a similar partner had a different goal or when a different partner had a similar goal. Thus, participants experienced expectancy violation regardless of whether the actual work goal of the dyad partner was similar to or different from their own work goal (see Table 1).

\section{Dependent measures}

Disappointment The results of the ANOVA on feelings of disappointment showed the predicted significant interaction between gender
Table 1. Means and standard deviations for the perception measures as a function of gender composition and work goal preference

\begin{tabular}{|c|c|c|c|c|}
\hline \multirow{3}{*}{ Gender composition: } & \multicolumn{4}{|c|}{ Work goal preference } \\
\hline & \multicolumn{2}{|c|}{ Similar } & \multicolumn{2}{|c|}{ Different } \\
\hline & $M$ & $S D$ & $M$ & $S D$ \\
\hline \multicolumn{5}{|l|}{ Expectancy violation } \\
\hline Similar & $3.13_{\mathrm{b}}$ & 1.36 & $4.80_{\mathrm{a}}$ & 1.04 \\
\hline Different & $5.07_{\mathrm{a}}$ & 2.02 & $3.37_{\mathrm{b}}^{\mathrm{d}}$ & 2.02 \\
\hline \multicolumn{5}{|l|}{ Disappointment } \\
\hline Similar & $1.60 \mathrm{a}$ & 0.83 & $4.33_{\mathrm{b}}$ & 1.35 \\
\hline Different & $3.87_{\mathrm{b}}$ & 1.55 & $1.87_{\mathrm{a}}$ & 0.64 \\
\hline \multicolumn{5}{|l|}{ Image dyad partner } \\
\hline Similar & $4.57_{\mathrm{a}}$ & 1.33 & $3.60_{\mathrm{b}}$ & 1.14 \\
\hline Different & $3.33_{\mathrm{b}}$ & 0.77 & $4.80_{\mathrm{a}}$ & 0.84 \\
\hline \multicolumn{5}{|l|}{ Commitment } \\
\hline Similar & $5.76_{\mathrm{ac}}$ & 0.34 & $5.22_{\mathrm{b}}$ & 0.57 \\
\hline Different & $5.49_{\mathrm{ab}}^{\mathrm{ac}}$ & 0.67 & $6.02_{c}^{\mathrm{D}}$ & 0.44 \\
\hline
\end{tabular}

Note: Means that share any letter do not differ significantly from each other, $p<.05$ (simple main effects).

composition and work goal preferences $(F(1$, 56) $\left.=63.24, p<.001, \eta^{2}=.53\right)$. Participants felt relatively little disappointment either when they found out that an opposite-sex partner had indeed selected a different work goal or when a same-sex partner actually preferred a similar work goal as the self. Participants reported significantly more feelings of disappointment when their gender-based expectation of the dyad partner's work goal preference was violated, regardless of whether this implied that the partner actually had selected a similar or different work goal (Table 1).

Image of the dyad partner The ANOVA on the image of the dyad partner also revealed the predicted significant interaction between gender and work goal preferences $(F(1,56)=$ $\left.20.30, p<.001, \eta^{2}=.27\right)$. As hypothesized, participants developed a clear image of a same-sex partner who favored a similar work goal, and of an opposite-sex partner who preferred a different work goal as the self. The dyad partner's image was less clear to participants when a 
same-sex partner unexpectedly turned out to prefer a different goal, or when an opposite-sex partner had actually selected a similar work goal as the self (see Table 1).

Commitment As predicted, there was also a significant two-way interaction effect between gender and work goal preferences on commitment $\left(F(1,56)=15.70, p<.001, \eta^{2}=.22\right)$. In line with our other findings it turned out that in the opposite-sex conditions, participants felt more committed toward future collaboration when the partner had selected a different work goal than when this partner unexpectedly preferred a same goal. In the same-sex conditions, participants also felt marginally more committed toward collaboration when the partner preferred a similar goal as the self than when participants found out that this partner actually favored a different work goal (Table 1). To conclude, participants generally responded more positively toward the other and the joint collaboration in the situation where their gender-based expectations of the dyad partner were confirmed than when these expectations were violated.

\section{Discussion}

The results of our study are in line with what we predicted and show that gender plays an important role in the extent to which people expect their collaborative partners to prefer a similar or a different work goal than the self. That is, people who anticipated an interaction with an opposite-sex partner expected the other to prefer a different work goal to the self, whereas those who thought they would be interacting with a same-sex partner expected this partner to have a similar work goal as the self. As expected, we additionally found that work goal diversity does not necessarily have a negative influence on the initial stages of dyadic decision making, provided that these differences were expected to occur due to gender differences. As long as work goal differences are expected, they will be less problematic for the ensuing collaboration in the sense that people remain committed to working together. That is, in the present study, people reported relatively little disappointment, developed a clear image of their dyad partner, and felt committed toward future collaboration when an oppositesex partner turned out to prefer a different work goal, or when a same-sex partner had selected a similar work goal as the self. This was less the case when the partner was thought to be of the same-sex, yet preferred a different work goal, or when the partner was thought to be of the opposite sex but unexpectedly turned out to prefer a similar work goal as the self. That is, people responded more positively toward the joint collaboration when their gender-based expectations were confirmed, than when these expectations were violated.

To examine the robustness of these findings, we conducted additional research using a slightly different methodology (Rink \& Ellemers, in press). In this further research, expectancies about task-related differences (which refer either to work goals or work styles) were explicitly induced, and participants did not receive any additional personal or demographic information about their partner prior to the collaboration. Across these studies we consistently observed that participants reported less disappointment, felt more committed toward the collaboration with their partner, and developed a clearer image of their partner when initial expectancies were confirmed, compared to when they were disconfirmed. Notably, these effects emerged, regardless of whether one's partner actually turned out to be similar to or different from the self.

We believe that these further studies increase confidence in the replicability of our current findings, as they show that expectancy-violation effects are observed regardless of whether initial expectancies of task-related differences are experimentally induced, or based on partner gender (as in the present research), and emerge regardless of whether similarities and differences pertain to work goals (as in the present research) or other types of task-related differences, and regardless of whether people only anticipate an interaction with their partner (as in the present research), or discover that they are similar or different during 
the interaction with their partner (Rink \& Ellemers, 2006a).

The present study offers an important and unique contribution to previous research because it examines the circumstances under which people develop task-related diversity expectancies on the basis of demographic differences. This is highly relevant to the theoretical notion that people should expect congruence between the social category and task-related attributes of their collaborative partners (Phillips, 2003). Consistent with the basic assumption of the trait model, our findings are the first to directly demonstrate that people impute non-stereotypical task-related attributes to others with whom they must collaborate on a task on the basis of whether those others are of similar or different gender as oneself. Furthermore, we were able to show that people prefer a congruent situation over an incongruent situation (McGrath et al., 1995; see also Orlitzky \& Benjamin, 2003; Phillips et al., 2004). Importantly, congruence was also preferred when people had to work with an opposite-sex partner who preferred a different work goal.

\section{Limitations and future research issues}

There are a few issues that would be worthwhile to examine in future research. First of all, we chose to use an experimental design so that we could examine the specific psychological processes underlying the relationship between gender diversity and work goal diversity in dyads under controlled conditions. In doing so, we were able to exclude other possible moderating factors that might influence the development of people's self-activated expectancies in more natural settings (see also Dipboye, 1990; Mook, 1983). Yet, we acknowledge that as a next step, it is important to examine the robustness of our findings in natural settings as well (see Jackson et al., 2003).

Furthermore, we explicitly focused on the initial stages of a new collaboration because an expectancy violation is in itself typically associated with instant negative reactions that ensue directly from this experience (e.g. disappointment, MacDowell \& Mandler, 1989). However, an interesting possibility for future research would be to examine how the negative impact of initially violated expectancies affects the further decision making process. Possibly, this depends on the nature of an expectancy violation (i.e. leading either to unexpected differences or unexpected similarities). That is, based on the similarity/attraction paradigm which proposes that people are in principle attracted to others who are similar to the self (Byrne, 1971), one can argue that people will probably be inclined to evaluate the presence of unexpected differences within their group more negatively than unexpected similarities. An expectancy violation resulting in unexpected work goal similarities will most likely elicit initial negative responses, but it might only complicate the further group discussion when group members realize that the availability of unique perspectives and the discussion of different priorities is critical for effective group performance (e.g. when groups have to work on complicated problem-solving tasks; Stasser \& Titus, 1985). When in contrast the existence of work goal differences implies interpersonal conflict and task disruption, the initial negative effects of unexpected work goal similarities may be overcome by their eventual facilitative effects on task performance.

One other point of interest is that we only used female participants in our study, and we deliberately introduced two work goals that were equally attractive to both men and women. This way, we excluded the possibility that the participants did not in fact develop male-stereotype expectations. Expectancy violation and congruence theory do not assume that systematic differences exist in the way certain social categories (e.g. members of minority groups vs. members of majority groups) react to unexpected situations. Yet, there is evidence to suggest that such differences can exist (Ashmore, Del Boca, \& Wohlers, 1986; Foschi, 2000). For instance, it has been well documented that minority members are more aware of their inferior position in relation to majority members than vice versa (e.g. Biernat \& Kobrynowicz, 1997; Glick et al., 2004). It might therefore well be that a minority member will 
expect a majority member to be different from the self on important task-related attributes, whereas a majority member does not expect such further differences to exist between the self and a minority member. Thus, it would be interesting to examine whether minority members differ from majority members in the extent to which they expect and eventually cope with task-related differences within their group or dyad (see also Chatman \& O'Reilly, 2004; Hollingshead \& Fraidin, 2003; ThomasHunt \& Phillips, 2004).

Finally, in this study we highlighted the importance of studying the relationship between gender diversity and work goal diversity. Future research could extend these insights by explicitly examining whether people also expect other demographic diversity attributes (e.g. culture, age, ethnicity) to relate to more 'underlying' task-related diversity attributes and include other task-related aspects in this investigation beyond the personal work goals of people (e.g. the kind of knowledge people possess).

\section{Practical implications}

The study that we have presented offers valuable insights for organizations that have to cope with diversity issues. Our findings suggest that people are inclined to expect congruence between the demographic and task-related attributes of others. From this, we infer that a demographically diverse work force will have less trouble dealing with additional occurring taskrelated differences among the employees than a demographically homogeneous work force. Thus, especially organizations with a demographically homogeneous work force should explicitly propagate the positive value of taskrelated diversity. This way, it will be more likely that the employees will accept and effectively use possible unexpected differences.

When expectancies are violated, feelings of unease and discomfort due to violation of initial expectancies may influence further willingness to collaborate with others. Even though people will not always have the option to engage in such avoidance behavior at work, within most work-teams they still have different possibilities as to whom they prefer to work with, and whom they try to avoid. Thus, one other important practical implication that can be derived from this study is that organizations can in principle benefit from any kind of diversity within their work force (either non-task related demographic differences or task-related differences), as long as employees expect such differences to occur within the teams and dyads to which they belong.

\section{Notes}

1. In The Netherlands, students often have to conduct an individual research project for their master's thesis during their internship.

2. We also performed a repeated measures analysis that included the Personal Work Goal of participants as an additional between-subject factor to check whether the nature of the personal work goal preference influenced the results for the gender-based expectancies. This was not the case $(F<1)$.

3. Again, we initially performed a series of ANOVAs that included the Personal Work Goal of participants as an additional between-subject factor and found that the nature of the personal work goal preference did not influence any of the results for the manipulation checks or dependent measures $(F<1)$. Therefore, we reported the results of 2 (Gender Composition) $\times 2$ (Work Goal Preference) ANOVAs on all measures.

\section{Acknowledgment}

We would like to thank Nicole DuJardin for her help with the data collection.

\section{References}

Ashmore, R. D., Del Boca, F. K., \& Wohlers, A. J. (1986). Gender stereotypes. In R. D. Ashmore \& F. K. Del Boca (Eds.), The social psychology of female-male relations. Orlando, FL: Academic Press.

Berger, J., Fisek, M. H., Norman, R. Z., \& Zelditch, M. (1977). Status characteristics and social interaction: An expectation-states approach. New York: Elsevier.

Berger, J., Ridgeway, C. L., Fisek, M. H., \& Norman, R. Z. (1998). The legitimation and delegitimation of power and prestige orders. American Sociological Review, 63, 379-405. 
Bettencourt, B. A., Dill, K. E., Greathouse, S., Charlton, K., \& Mulholland, A. (1996).

Evaluations of in-group and out-group members: The role of category-based expectancy violation. Journal of Experimental Social Psychology, 33, 244-275.

Biernat, M., \& Kobrynowicz, D. (1997). Gender- and race-based standards of competence: Lower minimum standards but higher ability standards for devalued groups. Journal of Personality and Social Psychology, 72, 544-557.

Biernat, M., Vescio, T. K., \& Billings, L. S. (1999). Black sheep and expectancy violation: Integrating two models of social judgment. European Journal of Social Psychology, 29, 523-542.

Burgoon, J. K., Le Poire, B. A., \& Rosenthal, R. (1995). Effects of preinteraction expectancies and target communication on perceiver reciprocity and compensation in dyadic interaction. Journal of Experimental Social Psychology, 31, 287-321.

Byrne, D. (1971). The attraction paradigm. New York: Academic Press.

Carli, L. L., LaFleur, S. J., \& Loeber, C. C. (1995). Nonverbal behavior, gender, and influence. Journal of Personality and Social Psychology, 6, 1030-1041.

Chatman, J. A., \& O'Reilly, C. A. (2004). Asymmetric reactions to work group sex diversity among men and women. Academy of Management Journal, 47, 193-211.

Connor, P. E., \& Becker, B. W. (1975). Values and the organization: Suggestions for research. Academy of Management Journal, 18, 550-561.

Dipboye, R. L. (1990). Laboratory vs. field research in industrial and organizational psychology. In C. L. Cooper \& I. T. Robertson (Eds.), International review of industrial and organizational psychology (Vol. 5). New York: Wiley.

Dose, J. J. (1997). Work values: An integrative framework and illustrative application to organizational socialization. Journal of Occupational and Organizational Psychology, 70, 219-240.

Eagly, A. H., \& Karau, S. J. (2002). Role congruity theory of prejudice toward female leaders. Psychological Review, 3, 573-598

Eagly, A. H., Karau, S. J., \& Makhijani, M. G. (1995). Gender and the effectiveness of leaders: A metaanalysis. Psychological Bulletin, 1, 125-145.

Ely, R. J., \& Thomas, D. A. (2001). Cultural diversity at work: The effects of diversity perspectives on work group processes and outcomes. Administrative Science Quarterly, 46, 229-273.

Fiske, S. T., \& Taylor, S. E. (1991). Social cognition (2nd. ed). New York: McGraw-Hill.

Foschi, M. (2000). Double standards for competence: Theory and research. Annual Review of Sociology, 26, 21-42.

Frijda, N. H., Kuipers, P., \& Ter Schure, E. (1989). Relations among emotion, appraisal, and emotional action readiness. Journal of Personality and Social Psychology, 57, 667-686.

Glick, P., Lameiras, M., Fiske, S. T., Eckes, T., Masser, B., Volpato, C., Manganelli, A. M., Pek, J., Huang, L., Sakalli-Uğurlu, N., Castro, Y. R., Luiza, M., Pereira, D., Willemson, T. M., Brunner, A., Materna, I., \& Wells, R. (2004). Bad but bold: Ambivalent attitudes toward men predict gender inequality in 16 nations. Journal of Personality and Social Psychology, 86, 713-728.

Gruenfeld, D. H., Mannix, E. A., Williams, K. Y., \& Neale, M. A. (1996). Group composition and decision making: How member familiarity and information distribution affect process and performance. Organizational Behavior and Human Decision Processes, 67, 1-15.

Harrison, D. A., Price, K. H., \& Bell, M. P. (1998). Beyond relational demography: Time and the effects of surface and deep-level diversity on group functioning. Academy of Management Journal, 41, 96-107.

Harrison, D. A., Price, K. H., Gavin, J. H., \& Florey, A. T. (2002). Time, teams, and task performance: Changing effects of surface- and deep-level diversity on group functioning. Academy of Management Journal, 45, 1029-1045.

Hollingshead, A. B., \& Fraidin, S. N. (2003). Gender stereotypes and assumptions about expertise in transactive memory. Journal of Experimental Social Psychology, 39, 355-363.

Jackson, S. E., Joshi, A., \& Erhardt, N. L. (2003). Recent research on team and organizational diversity: SWOT analysis and implications. Journal of Management, 29, 801-830.

Jehn, K. A., Northcraft, G. B., \& Neale, M. A. (1999). Why differences make a difference: A field study of diversity, conflict and performance in workgroups. Administrative Science Quarterly, 44, 741-763.

Jost, J. T., Kruglanski, A. W., \& Nelson, T. O. (1998). Social metacognition: An expansionist review. Personality and Social Psychology Review, 2, 137-154.

Kunda, Z., \& Spencer, S. J. (2003). When do stereotypes come to mind and when do they color judgment? A goal-based theoretical framework for stereotype activation and application. Psychological Bulletin, 4, 522-544.

Lawrence, B. S. (1997). The black box of organizational demography. Organizational Science, 8, 1-22. 
MacDowell, K. A., \& Mandler, G. (1989). Constructions of emotion: Discrepancy arousal and mood. Motivation and Emotion, 13, 105-124.

McGrath, J. E., Berdahl, J. L., \& Arrow, H. (1995). Traits, expectations, culture, and clout: The dynamics of diversity in work groups. In S. E. Jackson \& M. N. Ruderman (Eds.), Diversity in work teams: Research paradigms for a changing work place (pp. 17-146). Washington, DC: American Psychological Association.

Miller, N., \& Marks, G. (1982). Assumed similarity between self and other: Effect of expectation of future interaction with that other. Social Psychology Quarterly, 45, 100-105.

Mook, D. G. (1983). In defense of external validity. American Psychologist, 4, 379-386.

Nickerson, R. S. (1999). How we know-and sometimes misjudge-what others know: Imputing one's own knowledge to others. Psychological Bulletin, 125, 737-759.

Oldmeadow, J., \& Postmes, T. (2005). Social identity in interaction: Effects of status security on task-focused interactions and status beliefs. Manuscript submitted for publication.

Orlitzky, M., \& Benjamin, J. D. (2003). The effects of sex composition on small-group performance in a business school: A case competition. Academy of Management Learning and Education, 2, 128-138.

Pelled, L. H., Eisenhardt, K. M., \& Xin, K. R. (1999). Exploring the black box: An analysis of work group diversity, conflict, and performance. Administrative Science Quarterly, 44, 1-28.

Phillips, K. W. (2003). The effects of categorically based expectations on minority influence: The importance of congruence. Personality and Social Psychology Bulletin, 29, 3-13.

Phillips, K. W., Mannix, E. A., Neale, M. A., \& Gruenfeld, D. A. (2004). Diverse groups and information sharing: The effects of congruent ties. Journal of Experimental Social Psychology, 40, 497-510.

Rink, F., \& Ellemers, N. (in press). Diversity as a source of common identity: Towards a social identity framework for studying the effects of diversity in organizations. Manuscript submitted for publication.

Rink, F., \& Ellemers, N. (2006a). Benefiting from informational differences: How diversity can help focus on common group goals. Working paper: Leiden University, The Netherlands.

Stasser, G., \& Titus, W. (1985). Pooling of unshared information in group decision making: Biased information sampling during discussion. Journal of Personality and Social Psychology, 48, 1467-1478.

Thomas-Hunt, M. C., \& Phillips, K. W. (2004). When what you know is not enough: Expertise and gender dynamics in task groups. Personality and Social Psychology Bulletin, 30, 1585-1598.

Webber, S. S., \& Donahue, L. M. (2001). Impact of highly and less job related diversity on work group cohesion and performance: a meta analysis. Journal of Management, 27, 141-162.

Williams, K. Y., \& O’Reilly, C. A. III (1998).

Demography and diversity in organizations: A review of 40 years of research. In B. M. Staw \& L. L. Cummings (Eds.), Research in organizational behavior (Vol. 20, pp. 77-140). Greenwich, CT: JAI Press.

Zeelenberg, M., van Dijk, W. W., Manstead, A. S. R., \& van der Pligt, J. (1998). The experience of regret and disappointment. Cognition and Emotion, 12, 221-230.

Paper received 3 January 2005.

\section{Biographical notes}

FLOOR RINK is an Assistant Professor at Leiden University and conducts research that focuses on the social psychological mechanisms underlying group behavior and group performance. She is primarily interested in issues related to diversity and newcomer acceptance.

NAOMI ELLEMERS is a Professor at Leiden University and conducts basic and applied research, focusing on group processes and intergroup relations, and their effects on well-being, performance, and career development. She has published extensively on these topics in national and international journals, and has co-edited a number of books on social identity and stereotyping. 